Document downloaded from:

http://hdl.handle.net/10251/146185

This paper must be cited as:

Vanti, L.; Alauddin, SM.; Zaton, D.; Aripin, N.; Giaccinti-Baschetti, M.; Imrie, C.; RibesGreus, A.... (12-2). Ionically conducting and photoresponsive liquid crystalline terpolymers: Towards multifunctional polymer electrolytes. European Polymer Journal. 109:124-132. https://doi.org/10.1016/j.eurpolymj.2018.08.033

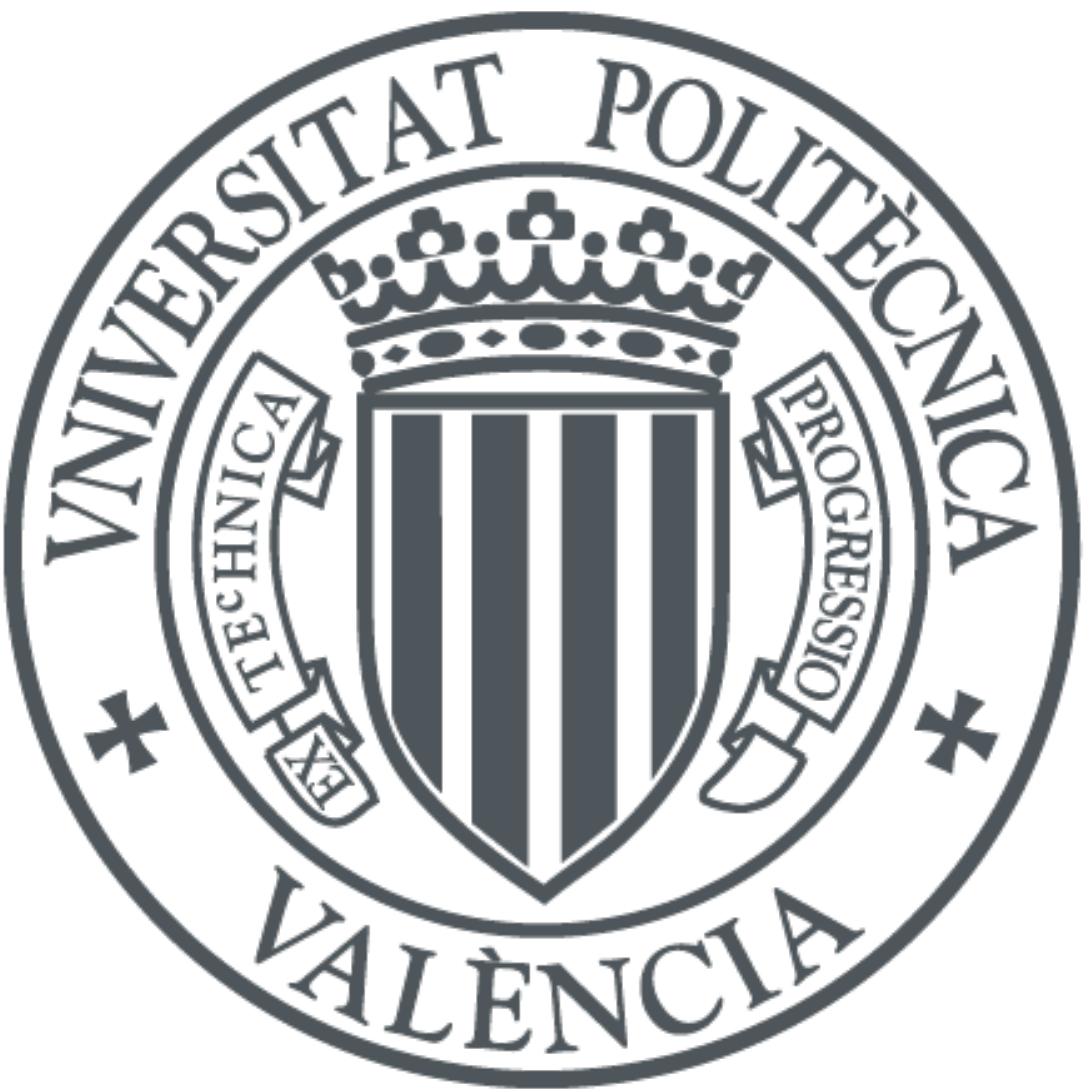

The final publication is available at

https://doi.org/10.1016/j.eurpolymj.2018.08.033

Copyright Elsevier

Additional Information 
L. Vanti, S. Mohd Alauddin, N. Fadhilah Binti Kamalul Aripin, M. Giacinti-Baschetti, C.T. Imrie, A. Ribes-Greus, A.

Martínez-Felipe. Ionically conducting and photoresponsive liquid crystalline terpolymers: towards multifunctional electrolytes. European Polymer Journal 2018; 109:124-132

\title{
IONICALLY CONDUCTING AND PHOTORESPONSIVE LIQUID CRYSTALLINE TERPOLYMERS: TOWARDS MULTIFUNCTIONAL ELECTROLYTES.
}

\author{
L. Vanti ${ }^{1}$, S. Mohd Alauddin², N. Fadhilah Binti Kamalul Aripin², M. Giacinti-
}

Baschetti ${ }^{1}$, C. T. Imrie ${ }^{3}$, A. Ribes-Greus ${ }^{4}$ and A. Martinez-Felipe ${ }^{5, *}$.

This is an open-access version, according to http://www.sherpa.ac.uk/romeo/issn/0014-3057/es/

Full text available at: https://www.sciencedirect.com/science/article/pii/S0014305718310413

DOI: https://doi.org/10.1016/j.eurpolymj.2018.08.033

Please, cite it as:

L. Vanti, S. Mohd Alauddin, N. Fadhilah Binti Kamalul Aripin, M. Giacinti-Baschetti, C.T. Imrie, A. RibesGreus, A. Martínez-Felipe. Ionically conducting and photoresponsive liquid crystalline terpolymers: towards multifunctional electrolytes. European Polymer Journal 2018; 109:124-132

${ }^{1}$ Department of Civil, Chemical, Environmental, and Materials Engineering, Università degli studi Bologna, Via Terracini 3440131 Bologna, Italy.

${ }^{2}$ Faculty of Chemical Engineering, University of Technology MARA, 40450 Shah Alam, Selangor Darul Ehsan, Malaysia.

${ }^{3}$ Chemistry, School of Natural and Computing Sciences, Meston Building, University of Aberdeen, Aberdeen AB24 3UE, Scotland, UK.

${ }^{4}$ Institute of Materials Technology, Universidad Politécnica de Valencia, Camino de Vera S/N, 46022 Valencia, Spain.

${ }^{5}$ Chemical and Materials Engineering Group, School of Engineering, University of Aberdeen, King's College, Aberdeen AB24 3UE, Scotland, UK.

*Corresponding author:

A. Martinez-Felipe a.martinez-felipe@abdn.ac.uk 


\title{
Ionically conducting and photoresponsive liquid crystalline terpolymers: towards multifunctional electrolytes.
}

L. Vanti, S. Mohd Alauddin, N. Fadhilah Binti Kamalul Aripin, M. Giacinti-Baschetti, C. T. Imrie, A. Ribes-Greus and A. Martinez-Felipe

\section{KEYWORDS}

side chain liquid crystal polymers, ionic conductivity, direct methanol fuel cells DMFCs, polymer electrolytes, light responsive materials.

\begin{abstract}
We have prepared a series of new ionically conducting electrolytes consisting of side-chain liquid crystal terpolymers with mesogenic azobenzenes, sulfonic acid groups and methyl methacrylates. The poly[10-(4-methoxyazobenzene -4'-oxy)decyl methacrylate]-co-poly[2acrylamido-2-methyl-1-propanesulfonic acid]-co-poly[methyl methacrylate]s, 10MeOAzB/AMPS/MMA terpolymers, were synthesised by a one-pot conventional radical polymerisation with a broad range of compositions. All samples were characterised by NMR, GPC/SEC, FT-IR, POM, XRD, DSC, UV-visible spectrophotometry and EIS. The terpolymers have light responsive character, and exhibit liquid crystallinity in a wide range of compositions, with the AMPS groups constrained between smectic layers. Above a certain threshold of acid contents, the 10-MeOAzB/AMPS/MMA terpolymers exhibit ionic conductivities in the $10^{-8}$ $10^{-4} \mathrm{~S} \cdot \mathrm{cm}^{-1}$ range, with signs of decoupling from segmental motions, making these compounds attractive candidates as low temperature electrolytes.
\end{abstract}


L. Vanti, S. Mohd Alauddin, N. Fadhilah Binti Kamalul Aripin, M. Giacinti-Baschetti, C.T. Imrie, A. Ribes-Greus, A.

Martínez-Felipe. Ionically conducting and photoresponsive liquid crystalline terpolymers: towards multifunctional electrolytes. European Polymer Journal 2018; 109:124-132

\section{INTRODUCTION}

The development of electrolytes with enhanced transport properties is paramount to improving the performance of electrochemical devices for energy conversion and storage ${ }^{1}$. Ion selective transport is a critical property, for example, in electrolytes for use in Direct Methanol Fuel Cells, DMFCs, and must facilitate high proton conductivity whilst preventing fuel crossover from anode to cathode ${ }^{2}$. Polymer electrolytes are particularly attractive for low temperature applications due to their relative low cost and high versatility, yielding a range of functionalities by chemical and physical modification ${ }^{3}$, and are at the core of batteries ${ }^{4}$ and proton exchange membrane fuel cells, PEMFCs 5 .

Conventional perfluorinated polymer electrolyte materials used in PEMFCs, such as Nafion, need water to create a phase separated structure consisting of hydrophilic clusters and channels for proton conduction ${ }^{6}$, favouring vehicular mechanisms of ion transport. The involvement of water limits the temperature of operation of hydrogen fuel cells, in order to avoid dehydration, and promotes fuel crossover through the electrolyte in DMFCs, ultimately decreasing cell efficiency ${ }^{7}$. In contrast, ion hopping mechanisms between ionic sites can yield more selective proton conductivity with respect to solvent diffusion ${ }^{8-10}$. Although a wide range of hydrocarbon-based polymers have been investigated as potential electrolytes in PEMFCs and DMFCs ${ }^{11-13}$, achieving simultaneous high proton selectivity and low solvent contents remains an unsolved challenge.

Thermotropic liquid crystals, LCs, offer alternative mechanisms to control the morphology of polymeric electrolytes in different applications ${ }^{14}$. Their anisotropic response to external stimuli, such as mechanical shearing, light, or magnetic and electrical fields, can be used to create preferential pathways for ionic conduction in the absence of solvents. In recent years, a wide variety of 1D-columnar, 2D-planar and 3D bicontinuous liquid crystalline materials have been proposed, for example, as electrolytes in batteries ${ }^{15}$. Among other advantages, liquid 
crystallinity may inhibit the crystallisation of poly(ethylene oxide), which has been extensively used as a polymer electrolyte for lithium ion batteries, thus increasing the mobility of lithium ions and cell performance ${ }^{16-18}$. The application of liquid crystals as electrolytes in PEMFCs and DMFCs, remains, however, largely unexplored ${ }^{19-22}$. Some selected examples include the work of Picken and co-workers, who have developed anisotropic proton conductivity in aligned poly(imides) ${ }^{23,24}$, and Montané et al., who studied calamitic and discotic electrolytes with columnar suprastructures that facilitate conductivity ${ }^{25}$. In these and similar materials, the fluidity of the mesophases can further promote local mobility, as occurs in ionic liquids and polymerised ionic liquids ${ }^{26-29}$, but with the potential of anisotropic control of the ion transport.

Recently, we have studied the phase behaviour and structure of new side chain liquid crystal polymers containing sulfonic acid groups ${ }^{30-32}$. Microphase separation between the backbone and the lateral groups confines the polar groups between smectic layers, resulting in potential anisotropic ionic pathways ${ }^{33-35}$. The strong interactions between the sulfonic acid groups, however, disrupt, at least to some extent, the formation of liquid crystalline phases, and restrict the compositional range over which mesogenic behaviour is observed in these materials 36,37 .

In the present work, we investigate the effect of including methyl methacrylate, as a third nonmesogenic/non-ionisable component, on the structure and conductivity of new side-chain terpolymers containing sulfonic acid and azobenzene units, the poly[10-(4methoxyazobenzene -4'-oxy)decyl methacrylate]-co-poly[2-acrylamido-2-methyl-1propanesulfonic acid]-co-poly[methylmethacrylate]s, 10-MeOAzB/AMPS/MMA, terpolymers, 1 , 
L. Vanti, S. Mohd Alauddin, N. Fadhilah Binti Kamalul Aripin, M. Giacinti-Baschetti, C.T. Imrie, A. Ribes-Greus, A.

Martínez-Felipe. Ionically conducting and photoresponsive liquid crystalline terpolymers: towards multifunctional electrolytes. European Polymer Journal 2018; 109:124-132
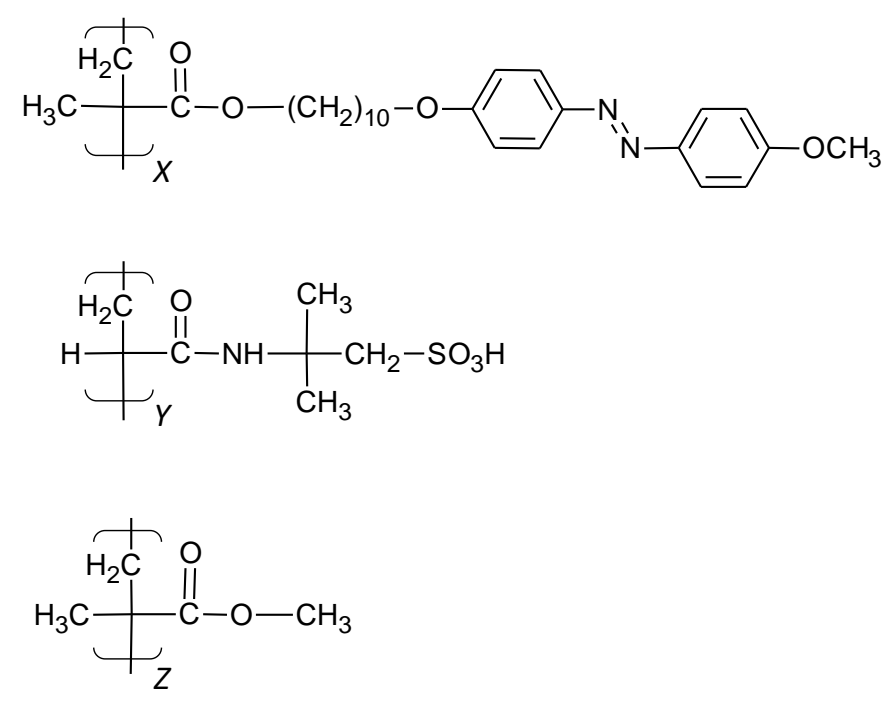

With the introduction of methacrylate units, we aim to regulate the interactions involving the conducting and mesogenic components, and promote the formation of different ultrastructures that enhance the conductivity and film forming properties of these materials. The presence of the azobenzene-based groups will allow control of their macroscopic properties using light stimuli via changes in the local order ${ }^{38-45}$. 
L. Vanti, S. Mohd Alauddin, N. Fadhilah Binti Kamalul Aripin, M. Giacinti-Baschetti, C.T. Imrie, A. Ribes-Greus, A.

Martínez-Felipe. Ionically conducting and photoresponsive liquid crystalline terpolymers: towards multifunctional electrolytes. European Polymer Journal 2018; 109:124-132

\section{EXPERIMENTAL SECTION}

\section{Synthesis and materials.}

The 10-MeOAzB/AMPS/MMA terpolymers, $\mathbf{1}$, were prepared over a broad range of compositions of the corresponding monomers: (i) the mesogenic side chains, 10-(4methoxyazobenzene -4'-oxy)decyl methacrylate, 10-MeOAzB, (ii) polar groups for solvating ions, acrylamido-2-methyl-1-propanesulfonic acids, AMPS, and (iii) methyl(methacrylate) groups, MMA, as non-mesogenic/non-ionic structure modifying units.

AMPS and MMA were commercially available from Sigma-Aldrich and used without further purification. 10-MeOAzB was prepared according to a procedure described in detail elsewhere 46-48. The 10-MeOAzB/AMPS/MMA terpolymers were prepared using a one-pot conventional free radical polymerisation under an inert atmosphere and appropriate amounts of the different monomers ${ }^{30}$. Further details of the synthetic procedure are provided in the Supplementary Information.

\section{Characterisation techniques.}

The chemical structures of all the terpolymers and their intermediates were verified using ${ }^{1} \mathrm{H}$ NMR, and Fourier transform infrared, FT-IR, spectroscopies. ${ }^{1} \mathrm{H}-\mathrm{NMR}$ spectra were measured using a Gemini 300 analyser in either $\mathrm{CDCl}_{3}$ or DMSO-d $\mathrm{d}_{6}$. FT-IR spectra were obtained using a Thermo Nicolet 5700 spectrometer for sample discs containing $1 \mathrm{mg}$ of product and $200 \mathrm{mg}$ of potassium bromide $(\mathrm{KBr}, \sim 0.5 \%$ by weight), prepared using a Specac 15 ton manual hydraulic press. The spectra were collected in Absorbance (Abs, \%) units as the average of 64 scans, in the $4000-400 \mathrm{~cm}^{-1}$ range, and with $4 \mathrm{~cm}^{-1}$ resolution. A background spectrum for a pristine $\mathrm{KBr}$ disc was measured before each series of experiments. Molecular weights and polydispersities of the polymers were assessed by gel permeation/size exclusion 
L. Vanti, S. Mohd Alauddin, N. Fadhilah Binti Kamalul Aripin, M. Giacinti-Baschetti, C.T. Imrie, A. Ribes-Greus, A.

Martínez-Felipe. Ionically conducting and photoresponsive liquid crystalline terpolymers: towards multifunctional electrolytes. European Polymer Journal 2018; 109:124-132

chromatography, GPC/SEC, using a Waters 1515 module with a refractive index detector (Waters 2414). Samples were eluted in tetrahydrofuran and diluted with a flow rate of $1 \mathrm{ml} / \mathrm{min}$ at $40^{\circ} \mathrm{C}$. Molecular weight calibration was performed using polystyrene standards.

The phase behaviour of the terpolymers was studied by polarised light microscopy, POM, using an Olympus BH-2 optical microscope equipped with a Linkam THMS 600 heating stage and a TMS 91 control unit, and the thermal transitions were determined by differential scanning calorimetry, DSC, using a Mettler Toledo DSC 822 analyser. Samples of around $5 \mathrm{mg}$ were heated from $25^{\circ} \mathrm{C}$ to $220^{\circ} \mathrm{C}$, held at $220^{\circ} \mathrm{C}$ for 3 minutes, cooled to $25^{\circ} \mathrm{C}$, held for 3 minutes, and re-heated to $220^{\circ} \mathrm{C}$. All the scans were performed at $10^{\circ} \mathrm{C} \cdot \mathrm{min}^{-1}$ under a nitrogen atmosphere and using liquid nitrogen as the coolant. The thermal stability of the samples was assessed by thermogravimetric analysis, TGA, using a Mettler Toledo TGA/SDTA 851 modulus. Around $5 \mathrm{mg}$ of sample in an $\mathrm{Al}_{2} \mathrm{O}_{3}$ pan containing a hole for gas release were heated from room temperature to $750^{\circ} \mathrm{C}$, at $10^{\circ} \mathrm{C} \cdot \mathrm{min}^{-1}$, under inert argon atmosphere with a flow rate of $200 \mathrm{ml} \cdot \mathrm{min}^{-1}$.

X-ray diffraction, XRD, patterns were obtained using a Bruker AXS D8 Discover X-ray diffractometer equipped with a Hi-Star 2D detector with $\mathrm{CuK} \alpha$-radiation filtered by crosscoupled Göbel mirrors at $40 \mathrm{kV}$ and $40 \mathrm{~mA}$. Samples were mounted on a piece of Scotch tape, heated to $150^{\circ} \mathrm{C}$, cooled slowly to room temperature, and their diffraction pattern recorded. The sample to detector distance was set to $13 \mathrm{~cm}$ and calibration of this distance was carried out using silver behenate as the reference. Molecular lengths were estimated using ACD/ChemSketch.

The UV-vis absorption spectra were recorded at room temperature using a Perkin Elmer Lamda 750 modulus spectrometer for $\sim 3.5 \times 10^{-5} \mathrm{M}$ tetrahydrofuran, THF, solutions of the 10MeOAzB/AMPS/MMA terpolymers. Concentrations were calculated on the basis of the compositions of the terpolymers assessed using ${ }^{1} \mathrm{H}-\mathrm{NMR}$ spectroscopy. Photoisomerisation of 
L. Vanti, S. Mohd Alauddin, N. Fadhilah Binti Kamalul Aripin, M. Giacinti-Baschetti, C.T. Imrie, A. Ribes-Greus, A.

Martínez-Felipe. Ionically conducting and photoresponsive liquid crystalline terpolymers: towards multifunctional electrolytes. European Polymer Journal 2018; 109:124-132

the azobenzenene units was investigated by placing the samples in quartz cuvettes at $10 \mathrm{~cm}$ from a compact UVGL-58 handheld 6Watt UV lamp, emitting at $365 \mathrm{~nm}$. After irradiation, the solutions were kept in the dark and their UV-vis spectra were recorded as a function of time for up to one day.

Ionic conductivity was measured using a Hioki 3532-50 LCR Hi tester in the frequency range of $50 \mathrm{~Hz}$ to $5 \mathrm{MHz}$, between 303 and $423 \mathrm{~K}$. A few milligrams of the terpolymer were melted on a stainless steel electrode (20 mm diameter, SUS316), allowed to cool slowly into the liquid crystal phase, covered with a second similar electrode, and then further cooled to room temperature. The electrodes were separated by a Teflon ring of internal diameter $12 \mathrm{~mm}$. Samples were heated above their clearing point inside the cell, and then measured in isothermal steps on cooling to room temperature. The results were obtained in terms of the complex dielectric permittivity, $\varepsilon^{*}=\varepsilon^{\prime}-i \varepsilon^{\prime \prime}$, where $i$ is the imaginary unit, which was transformed into the complex impedance, $Z^{*}$,and conductivity, $\sigma^{*}$, using:

$$
Z^{*}=Z^{\prime}+i Z^{\prime \prime}=\frac{1}{i \omega C_{0} \varepsilon^{*}}
$$

and

$$
\sigma^{*}=i \omega \varepsilon_{0} \varepsilon^{*}
$$

where $\omega$ is the angular frequency in $\mathrm{rad} \cdot \mathrm{sec}^{-1}, C_{0}$ is the cell capacitance and $\varepsilon_{0}$ is the permittivity in the vacuum, $8.854 \times 10^{-12} \frac{\mathrm{F}}{\mathrm{m}}$. 
L. Vanti, S. Mohd Alauddin, N. Fadhilah Binti Kamalul Aripin, M. Giacinti-Baschetti, C.T. Imrie, A. Ribes-Greus, A.

Martínez-Felipe. Ionically conducting and photoresponsive liquid crystalline terpolymers: towards multifunctional electrolytes. European Polymer Journal 2018; 109:124-132

\section{RESULTS AND DISCUSSION}

\section{Composition and molecular weight analysis.}

We refer to the 10-MeOAzB/AMPS/MMA terpolymers as AX/SY/MZ, where $X, Y$ and $Z$ are the molar percentages of 10-MeOAzB, AMPS and MMA, respectively, as assessed experimentally by ${ }^{1} \mathrm{H}-\mathrm{NMR}$ spectroscopy. Specifically, we calculated the composition in terms of the relative integrals of the $7-8 \mathrm{ppm}$ signals, assigned to the phenyl azobenzene protons $(4 \mathrm{H})$ of $10-\mathrm{MeOAzB}$, the $\sim 2.7 \mathrm{ppm}$ singlet, assigned to the methylene groups $(2 \mathrm{H})$ adjacent to the sulfonic acid groups in AMPS, and the peak at $\sim 3.6 \mathrm{ppm}$, associated with the methyl groups $(3 \mathrm{H})$ of MMA. The FT-IR spectra of the terpolymers contain bands characteristic of the functional groups in the individual components, including the carbonyl stretching bands from the ester groups in 10-MeOAzB and MMA $\left(\sim 1730 \mathrm{~cm}^{-1}\right)$ together with the $\mathrm{C}=\mathrm{O}$ stretching band $\left(\sim 1670 \mathrm{~cm}^{-1}\right)$ and the N-H stretching and bending signals ( 3400 and $\sim 1550 \mathrm{~cm}^{-1}$, respectively) from the amide groups in AMPS ${ }^{31}$. These observations are consistent with the proposed chemical structures of the polymers, 1 .

For the sake of comparison, we have divided the terpolymers into two main series, see Table 1. In samples \#1 to \#4 we keep the concentration of AMPS groups relatively low and vary the amount of MMA groups, whereas in samples \#5 to \#8 we explore a broader range of AMPS concentrations. The molecular weights of all the terpolymers were measured by gel permeation chromatography/size exclusion, GPC/SEC, and are also summarised in Table 1. The degrees of polymerisation for each terpolymer are sufficiently high to ensure that their transational properties do not lie in the strongly molecular weight dependent regime and thus comparisons may be made between them ${ }^{46}$. 
L. Vanti, S. Mohd Alauddin, N. Fadhilah Binti Kamalul Aripin, M. Giacinti-Baschetti, C.T. Imrie, A. Ribes-Greus, A.

Martínez-Felipe. Ionically conducting and photoresponsive liquid crystalline terpolymers: towards multifunctional electrolytes. European Polymer Journal 2018; 109:124-132

Table 1. Molecular weights, polydispersities, $M_{w} / M_{n}$, and number average degrees of polymerization, $D P$, for the 10-MeOAzB/AMPS/MMA terpolymers, 1 . Also listed are the feed compositions used in the copolymerisations. $X, Y$ and $Z$ are the molar percentages of 10-MeOAzB, AMPS and MMA, respectively, assessed experimentally.

\begin{tabular}{|c|c|c|c|c|c|c|}
\hline Sample & $\begin{array}{c}\text { AX/SY/MZ } \\
\text { Experimental }\end{array}$ & $\begin{array}{c}\text { AX/SY/MZ } \\
\text { Feed }\end{array}$ & $\begin{array}{c}\boldsymbol{M}_{\boldsymbol{n}} / \\
\mathbf{g} \cdot \mathbf{m o l}^{-\mathbf{1}}\end{array}$ & $\begin{array}{c}\boldsymbol{M}_{\boldsymbol{w}} / \\
\mathbf{g} \cdot \mathbf{m o l}^{-\mathbf{1}}\end{array}$ & $\boldsymbol{M}_{\boldsymbol{w}} / \boldsymbol{M}_{\boldsymbol{n}}$ & $\boldsymbol{D P}$ \\
\hline & P10-MeOAzB & $100 / 0 / 0$ & 12544 & 27094 & 2.2 & 28 \\
\hline (A100/S0/M0) & A70/S15/M15 & $72 / 18 / 10$ & 17390 & 60278 & 3.5 & 45 \\
\hline$\# 1$ & A55/S20/M25 & $48 / 12 / 40$ & 16139 & 47850 & 3.0 & 51 \\
\hline$\# 3$ & A50/S15/M35 & $64 / 16 / 20$ & 13204 & 28286 & 2.1 & 41 \\
\hline$\# 4$ & A41/S11/M48 & $32 / 08 / 60$ & 14308 & 31855 & 2.2 & 56 \\
\hline$\# 5$ & A61/S30/M09 & $63 / 27 / 10$ & 35284 & 784402 & 22.2 & 102 \\
\hline$\# 6$ & A29/S36/M35 & $33 / 33 / 33$ & 12698 & 83058 & 6.5 & 53 \\
\hline$\# 7$ & A43/S40/M17 & $45 / 45 / 10$ & 13064 & 48158 & 3.7 & 45 \\
\hline$\# 8$ & A09/S85/M06 & $36 / 54 / 10$ & 15687 & 212104 & 13 & 72 \\
\hline
\end{tabular}

\section{Thermal stability.}

The thermal stability of the terpolymers was assessed by thermogravimetric analysis, TGA, and the weight loss curves, TG, and corresponding derivative curves, DTG, are shown in Figures 1(a) and 1(b), respectively. Thermal degradation of the P10-MeOAzB homopolymer occurs through two main weight loss processes, which we attribute to the breakage of the more labile groups in the side chains, between $300^{\circ} \mathrm{C}$ and $400^{\circ} \mathrm{C}$, followed by decomposition of the polymer backbone, between $400{ }^{\circ} \mathrm{C}$ and $500^{\circ} \mathrm{C}$. In general terms, the terpolymers display a main weight loss around $400^{\circ} \mathrm{C}$, as well as an additional process at about $300^{\circ} \mathrm{C}$, see Figure 
L. Vanti, S. Mohd Alauddin, N. Fadhilah Binti Kamalul Aripin, M. Giacinti-Baschetti, C.T. Imrie, A. Ribes-Greus, A.

Martínez-Felipe. Ionically conducting and photoresponsive liquid crystalline terpolymers: towards multifunctional electrolytes. European Polymer Journal 2018; 109:124-132

1(b). This latter weight loss is presumably associated with the decomposition of the MMA and the AMPS units in the polymer chain. Terpolymers with high AMPS contents (samples \#6 to \#8) display additional processes below $300^{\circ} \mathrm{C}$, which could have contributions from the release of residual solvent trapped within the polymer structure ${ }^{6,30,49}$. The residual values of all the polymers under study after heating to $750^{\circ} \mathrm{C}$ fall within 15 to $20 \%$, in weight $\%$.

(a)

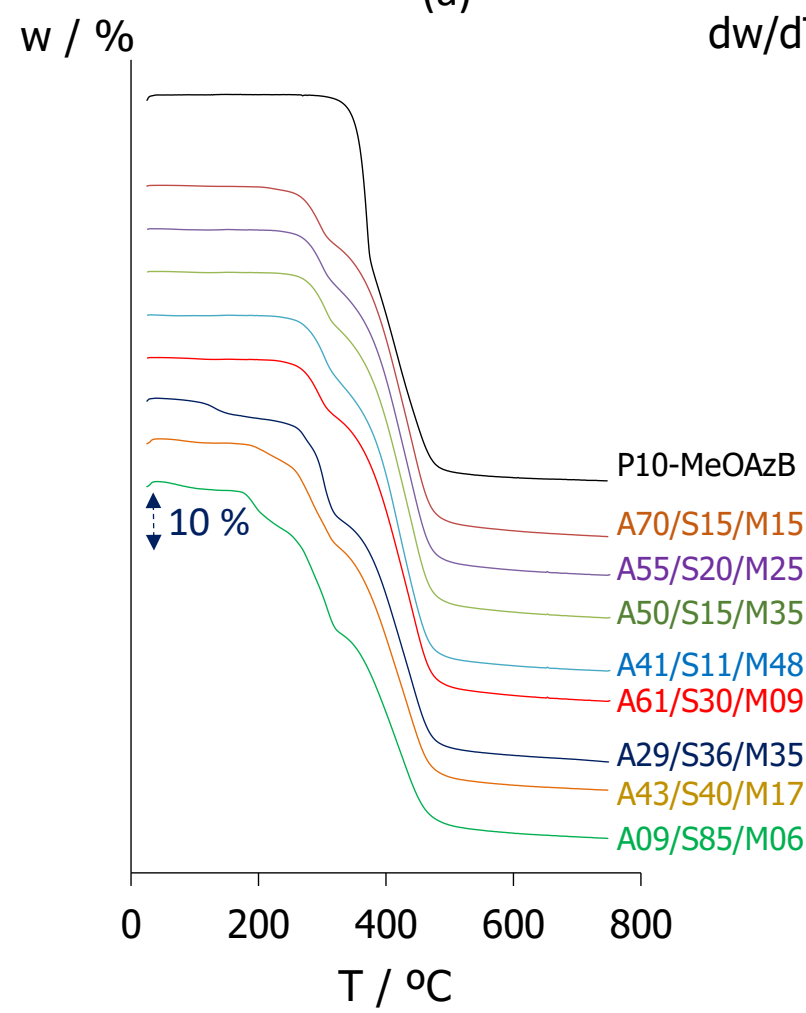

(b) P10-MeOAzB A70/S15/M15 A55/S20/M25 A50/S15/M35 A41/S11/M48 A61/S30/M09 A29/S36/M35 A43/S40/M17 A09/S85/M06

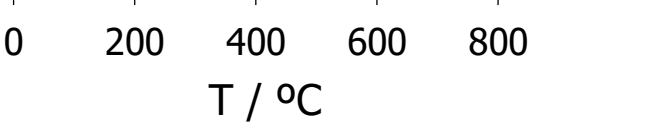

Figure 1. (a) Thermogravimetric curves, TG, and (b) derivative thermogravimetric curves, DTG, corresponding to the P10-MeOAzB homopolymer and the 10MeOAzB/AMPS/MMA terpolymers. Curves have been shifted arbitrarily along the Yaxes. 


\section{Phase behaviour.}

The transitional properties of the terpolymers are listed in Table 2. The 10-MeOAzB homopolymer, P10-MeOAzB, exhibits enantiotropic smectic A and nematic behaviour and vitrifies to form a smectic glass. The nematic phase is observed over a very narrow temperature range on cooling from the isotropic melt, and prior to the formation of the smectic A phase ${ }^{50}$. 10-MeOAzB/AMPS/MMA terpolymers with moderate and high concentrations of mesogenic units ( $\geq 29 \%$, molar) also show liquid crystallinity, assigned on the basis of the observation of fluid birefringent regions when viewed through the polarised optical microscope, POM. Unfortunately, the optical textures are not well-defined and were not useful for phase assignment.

The DSC traces obtained for the 10-MeOAzB/AMPS/MMA terpolymers in their second heating scans are shown in Figure 2. Terpolymers with $A>29 \%$ exhibit two distinct thermal events: a glass transition, $\mathrm{T}_{\mathrm{g}}$ (between $60{ }^{\circ} \mathrm{C}$ and $80{ }^{\circ} \mathrm{C}$ ), and a first order transition at higher temperatures, associated with the liquid crystal to isotropic transition, $\mathrm{T}_{\mathrm{LCI}}$, in excellent agreement with observations made using POM. The terpolymers tend to exhibit higher glass transitions than $\mathrm{P} 10-\mathrm{MeOAzB}$, presumably reflecting the less flexible poly(methyl methacrylate), PMMA $\left(\mathrm{T}_{\mathrm{g}}>100^{\circ} \mathrm{C}{ }^{51}\right)$, and PAMPS $\left(\mathrm{T}_{\mathrm{g}} \sim 124^{\circ} \mathrm{C}{ }^{30}\right)$ backbones. This increase is counteracted, at least to some extent, by a plasticizing effect of the flexible 10-MeOAzB side-chains. The terpolymer with the lowest mesogenic content $(A=9 \%)$ shows only a glass transition in the DSC trace, again consistent with the POM observation.

Reducing the concentration of mesogenic units in the terpolymers lowers the clearing point with respect to the $\mathrm{P} 10-\mathrm{MeOAzB}$ homopolymer and reduces the liquid crystal temperature 
L. Vanti, S. Mohd Alauddin, N. Fadhilah Binti Kamalul Aripin, M. Giacinti-Baschetti, C.T. Imrie, A. Ribes-Greus, A.

Martínez-Felipe. Ionically conducting and photoresponsive liquid crystalline terpolymers: towards multifunctional electrolytes. European Polymer Journal 2018; 109:124-132

ranges. The decrease in $\mathrm{T}_{\mathrm{LCI}}$ for most of the samples lies between 10 and $18^{\circ} \mathrm{C}$, and does not vary linearly with the concentration of mesogenic units. This is consistent with our previous report that the introduction of moderate amounts of AMPS chains causes small reductions in $\mathrm{T}_{\mathrm{LCI}}$ for the 10-MeOAzB/AMPS copolymers ${ }^{30}$. The data listed in Table 2 indicate that MMA has a stronger destabilising effect on liquid crystalline behaviour and the sample with the highest MMA concentration, A41/S11/M48, exhibits the lowest $\mathrm{T}_{\mathrm{LCI}}$.

Table 2. Transition temperatures and associated enthalpy, $\Delta \mathbf{H}_{\mathbf{L C I}}$, and entropy, $\Delta \mathbf{S}_{\mathbf{L C I}} / \mathbf{R}$, changes for $\mathrm{P} 10-\mathrm{MeOAzB}$ and the 10-MeOAzB/AMPS/MMA terpolymers.

\begin{tabular}{|c|c|c|c|c|c|c|}
\hline Sample & $\mathbf{A X} / \mathbf{S Y} / \mathbf{M Z}$ & $\begin{array}{c}\mathbf{T}_{\mathbf{g}} \\
\left({ }^{\mathbf{}} \mathbf{C}\right)\end{array}$ & $\begin{array}{c}\mathbf{T}_{\mathbf{L C I}} \\
\left({ }^{\mathbf{}} \mathbf{C}\right)\end{array}$ & $\begin{array}{c}\Delta \mathbf{H}_{\mathbf{L C I}} \\
\left(\mathbf{J} \cdot \mathbf{g}^{-1}\right)\end{array}$ & $\begin{array}{c}\Delta \mathbf{H}_{\mathbf{L C I}} \\
\left(\mathbf{k J} \cdot \mathbf{m o l}^{-1}\right)\end{array}$ & $\Delta \mathbf{S} \mathbf{L C I} / \mathbf{R}$ \\
\hline & $\begin{array}{c}\text { P10-MeOAzB} \\
(\mathrm{A} 100 / \mathrm{S} 0 / \mathrm{M} 0)\end{array}$ & 71 & 135 & 11.22 & 5.08 & 1.50 \\
\hline$\# 1$ & A70/S15/M15 & 72 & 125 & 5.38 & 2.13 & 0.64 \\
\hline$\# 2$ & A55/S20/M25 & 79 & 117 & 6.58 & 2.30 & 0.71 \\
\hline$\# 3$ & A50/S15/M35 & 76 & 125 & 5.59 & 2.14 & 0.65 \\
\hline$\# 4$ & A41/S11/M48 & $* *$ & 97 & 7.84 & 2.32 & 0.75 \\
\hline$\# 5$ & A61/S30/M09 & 72 & 126 & 5.38 & 2.13 & 0.64 \\
\hline$\# 6$ & A29/S36/M35 & 82 & 120 & 3.08 & 0.76 & 0.23 \\
\hline$\# 7$ & A43/S40/M17 & 76 & 128 & 5.78 & 2.13 & 0.64 \\
\hline$\# 8$ & A09/S85/M06 & 64 & - & - & - & - \\
\hline
\end{tabular}

* Enthalpy, $\Delta \mathbf{H}_{\mathbf{L C I}}$, and entropy, $\Delta \mathbf{S} / \mathbf{R}_{\mathbf{L C I}}$, values corresponding to merged isotropic to nematic and nematic to smectic A transitions ${ }^{52}$.

** Overlapped with first-order transition. 


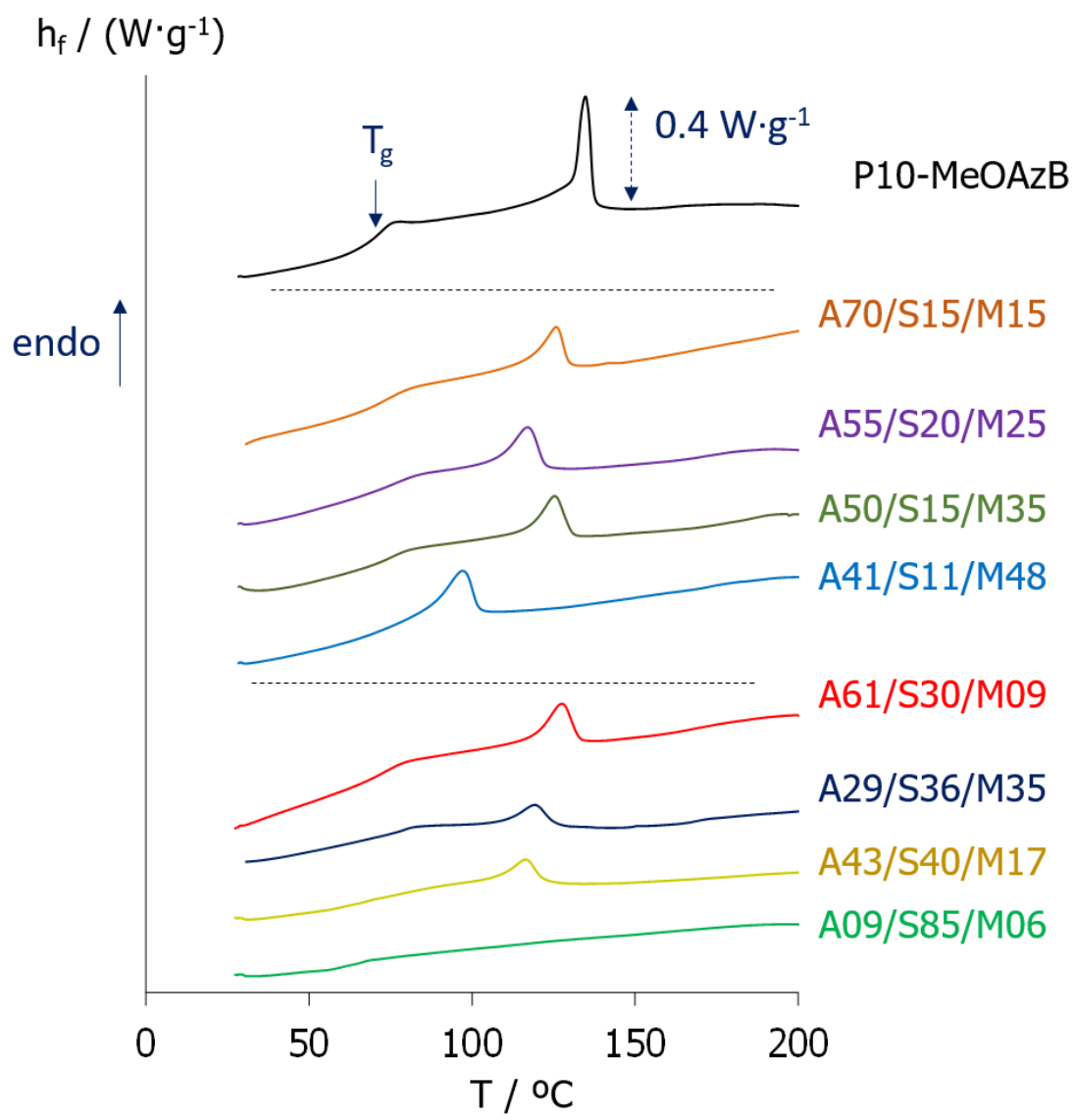

Figure 2. DSC traces corresponding to the second heating scans of the 10MeOAzB/AMPS/MMA terpolymers. Curves have been shifted arbitrarily along the Y-axis.

\section{Phase structure.}

Figure 3 shows the X-ray diffraction patterns of the terpolymers obtained at room temperature after cooling slowly from the isotropic or liquid crystalline phase. The P10MeOAzB diffractogram in Figure 3(a) contains a strong reflection in the small angle region, $2 \theta_{1} \sim 5.74^{\circ}$, and a broad diffuse reflection at wider angles, $2 \theta_{2} \sim 12^{\circ}$. The wider angle reflection corresponds to the periodicity along the polymer backbone $\left(d_{2} \sim 7.4 \AA\right)$. The lowangle reflection corresponds to the smectic periodicity $\left(d_{l} \sim 15.7 \AA\right)$ and is approximately half the length of the mesogenic 10-MeOAzB side chains in all-trans conformations, $l \sim 32$ $\AA$. This suggests a fully interleaved standard smectic A phase $\left(\mathrm{SmA}_{1}\right)$, see Figure $4(\mathbf{a})^{53}$. 
L. Vanti, S. Mohd Alauddin, N. Fadhilah Binti Kamalul Aripin, M. Giacinti-Baschetti, C.T. Imrie, A. Ribes-Greus, A.

Alternatively, however, the ratio $d_{l} / l \sim 0.5$ may reflect a quasi-symmetrical distribution of the electronic density about the mid-point of the smectic layers and the backbone domains 50.

(a)

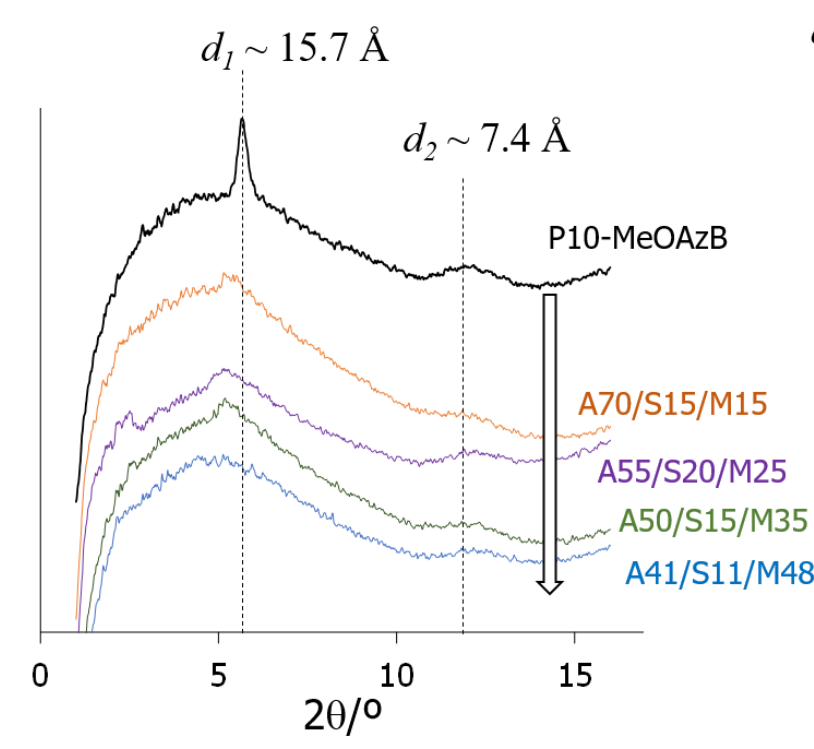

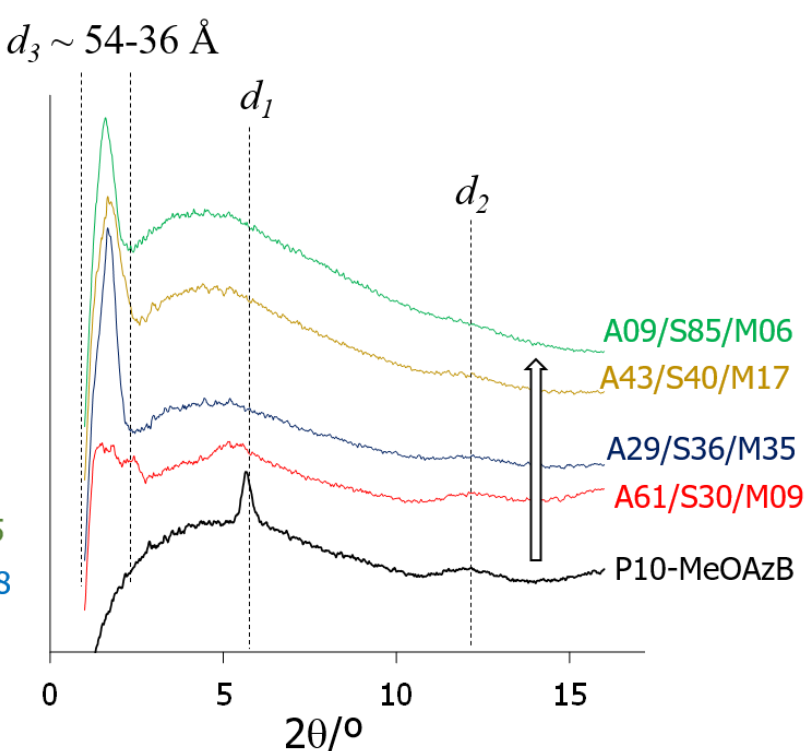

Figure 3. XRD diffraction patterns obtained at room temperature on cooling from the liquid crystal/isotropic phases of the 10-MeOAzB/AMPS/MMA terpolymers. (a) Effect of increasing MMA content in samples \#1 to \#4; (b) increasing AMPS content in samples \#5 to \#8. Arrows indicate decreasing mesogenic content. Y-axes correspond to the diffractogram intensity, a.u., and curves have been shifted arbitrarily along this axis.

The XRD patterns of the terpolymers contain similar reflections in the same small and wide angle regions as described for the pattern of $\mathrm{P} 10-\mathrm{MeOAzB}$, confirming the phase assignment made by POM, which also is consistent with the magnitudes of the associated enthalpy changes listed in Table $2^{53}$. On increasing MMA content, the intensity of the small angle peak decreases and shifts towards lower $2 \theta$ values, Figure 3(a), evidencing the disruption of the smectic layers arising from the dilution of the mesogenic units. In order to accommodate the increasing 
number of non-mesogenic units, the polymer backbone of the terpolymers is distorted, facilitating interfacial mixing between the main chain and the 10-MeOAzB side groups. This effectively swells the layer giving larger spacings (up to $d_{l} \sim 18.3 \AA$ ).

(a)

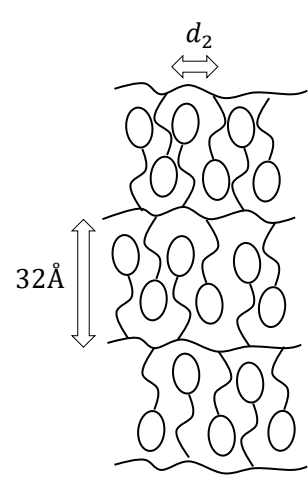

$\mathrm{P} 10-\mathrm{MeOAzB}$

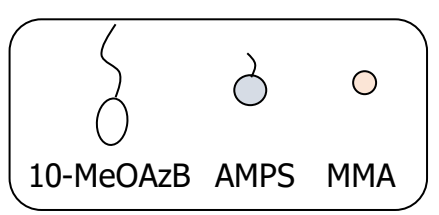

(b)

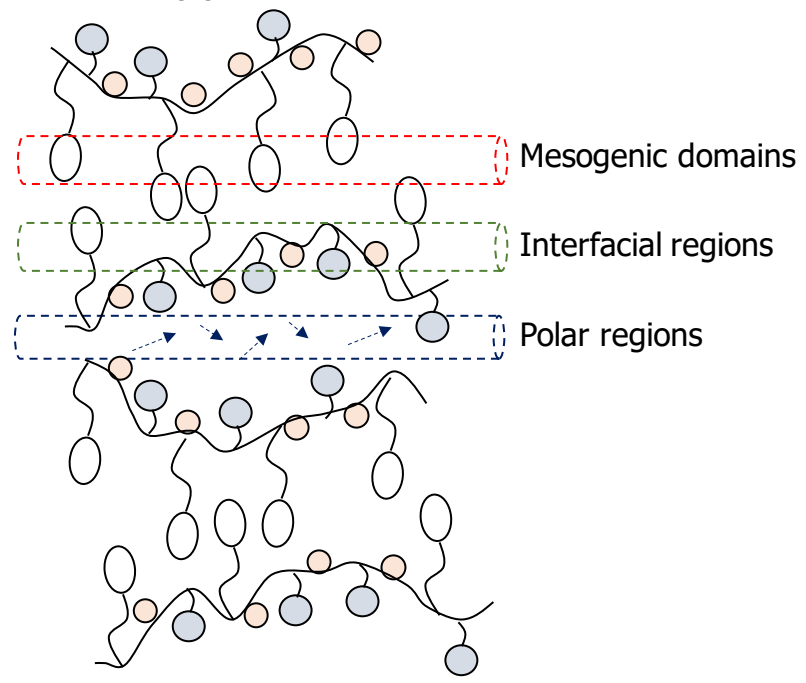

Figure 4. Proposed structural models for the smectic phases shown by (a) P10-MeOAzB and (b) the 10-MeOAzB/AMPS/MMA terpolymers containing equal amounts of the three components, showing coexisting smectic and acid domains. Dotted arrows indicate potential ionically conducting pathways.

The presence of large amounts of AMPS in samples \#5 to \#8 is associated with the appearance of a strong reflection at small angles, $2 \theta_{3} \sim 1.70-2.54^{\circ}$, see Figure 3(b), which we assign to the formation of polar aggregates in the terpolymers ${ }^{52}$. The nature of the interactions involving the AMPS units may be investigated using FT-IR spectroscopy, and the spectra of the terpolymers measured at room temperature are shown in Figure 5. It is noteworthy that the O$\mathrm{H}$ stretching (st.) region (expected between 3400 and $3500 \mathrm{~cm}^{-1}$ ) is rather weak and overlaps 
the stronger N-H st. band $\left(v \sim 3300 \mathrm{~cm}^{-1}\right)$. This differs from the spectra of the 10MeOAzB/AMPS copolymer system, and suggests that the sulfonic acid groups $\left(\mathrm{SO}_{3} \mathrm{H}\right)$ in the AMPS units may be, at least partially, depronotated in the terpolymers. The presence of sulfonate groups is also consistent with the increase in the IR contribution around $1034 \mathrm{~cm}^{-1}$ at higher AMPS concentrations, assigned to the $\mathrm{SO}_{3}^{-}$st. vibration ${ }^{31}$, see inset in Figure 5.

The appearance of the strong small angle reflection on increasing AMPS content in the terpolymers, Figure 3, indicates the co-existence of smectic domains and ionic regions even at moderate concentrations of AMPS ( $\mathrm{Y} \geq 30 \%$, molar). This suggests that the AMPS units are squeezed between alternating smectic layers that are further stabilised by micro-phase separation between polar and non-polar domains, see Figure 4(b). The appearance of the NH st. band in Figure 5 at relatively low frequencies $\left(v<3400 \mathrm{~cm}^{-1}\right)$ and the presence of Fermi bands in the vicinity of $v \sim 2500 \mathrm{~cm}^{-1}$, are indicative of the existence of extensive hydrogen bonding ${ }^{54-57}$ near the backbone. Such strong interactions may further contribute to stabilise the smectic order by constraining the mobility of the neighbouring $10-\mathrm{MeOAzB}$ side chains ${ }^{32}$, 36. The methyl methacrylate units in the terpolymers seem to weaken the interactions between the AMPS groups located in the backbone, mitigating to some extent these stabilising effects and further reducing $\mathrm{T}_{\mathrm{LCI}}$ and $\Delta \mathrm{S}_{\mathrm{LCI}} / \mathrm{R}$. The low entropy values in Table 2 together with the broader transition peaks in Figure 2 at higher MMA contents, are indeed signatures of some interfacial mixing between polar and non-polar domains in those terpolymers ${ }^{58-60}$. 
L. Vanti, S. Mohd Alauddin, N. Fadhilah Binti Kamalul Aripin, M. Giacinti-Baschetti, C.T. Imrie, A. Ribes-Greus, A.

Martínez-Felipe. Ionically conducting and photoresponsive liquid crystalline terpolymers: towards multifunctional electrolytes. European Polymer Journal 2018; 109:124-132

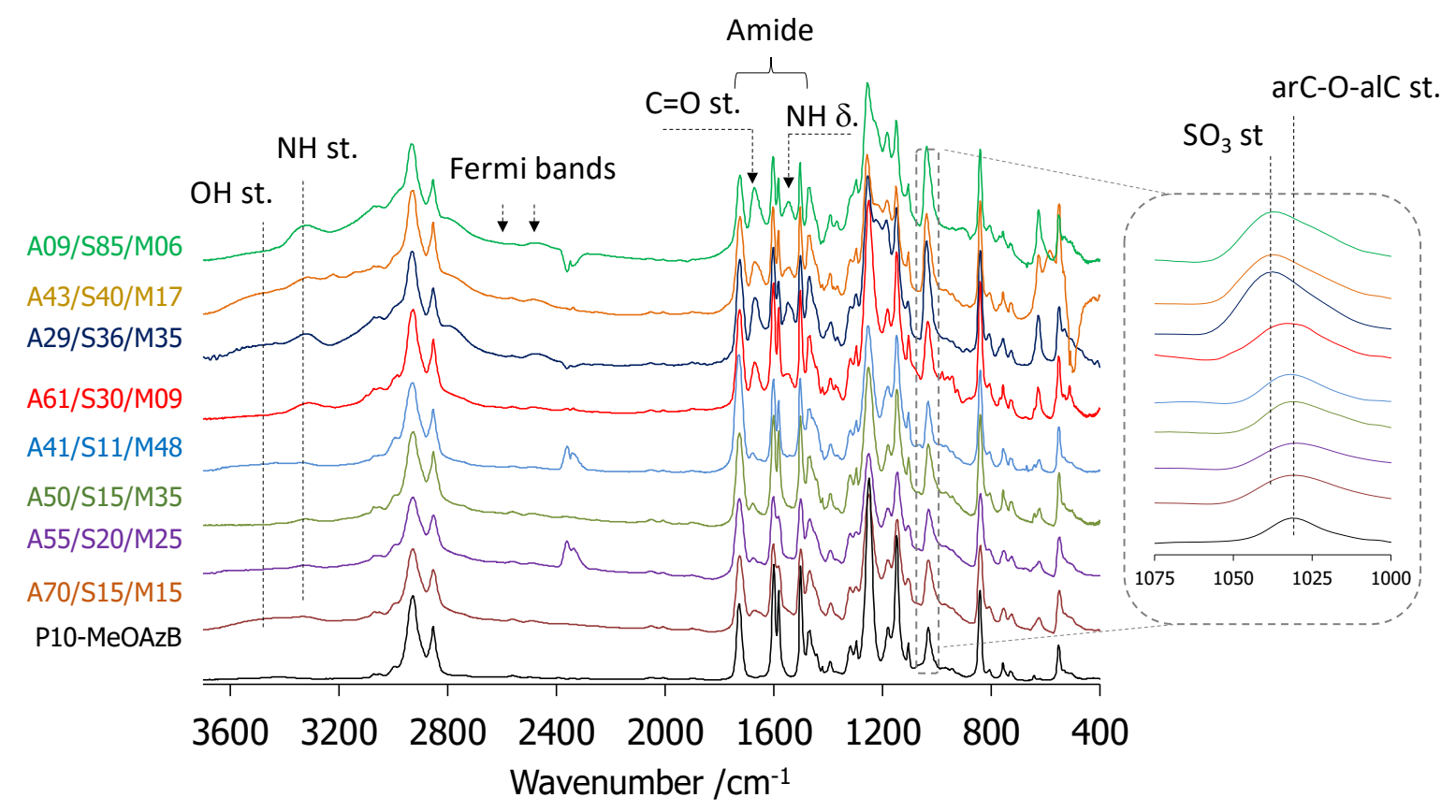

Figure 5. FT-IR spectra of the terpolymers, highlighting the contributions from the AMPS units. Inset shows the $\mathrm{SO}_{3}$ stretching band, which overlaps the stretching vibration band of the ether linkage between the azobenzene groups and alkyl chains in 10-MeOAzB, arC-O-alC st. The Y-axis displays IR absorbance (a.u.) with the spectra shifted arbitrarily along this axis.

\section{Light responsive behaviour.}

We now turn our attention to the photo-responsive nature of the 10-MeOAzB/AMPS/MMA terpolymers and discuss the dependence of the UV-vis spectra of $\sim 10^{-5} \mathrm{M}$ THF polymer solutions following UV radiation. The UV-vis spectra of the P10-MeOAzB homopolymer contains two main absorption regions associated with the $E$-isomer of the azobenzene unit, Figure 6(a): an intense band centred at $\sim 362 \mathrm{~nm}$, corresponding to the $\pi-\pi^{*}$ transition, and a weak absorption at $\sim 450 \mathrm{~nm}$, associated with the symmetric forbidden $n-\pi^{*}$ transition ${ }^{61}$. The maximum at $362 \mathrm{~nm}$ may be assigned to contributions from non-aggregated $E$-azobenezene units ${ }^{62}$. The UV-vis spectra of the terpolymers show similar spectra to P10-MeOAzB, 
confirming that the photo responsive character of the azobenzene units is maintained after copolymerisation. As expected, reducing the azobenzene content weakens the UV signals for the terpolymers, but otherwise their spectra are essentially identical, suggesting that the azobenzene moieties respond similarly to light exposure.

(a)

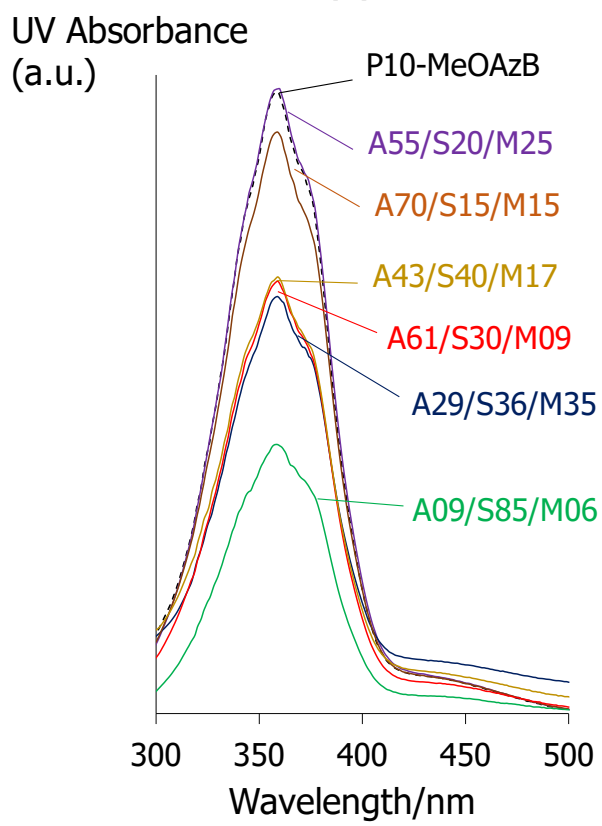

(b)

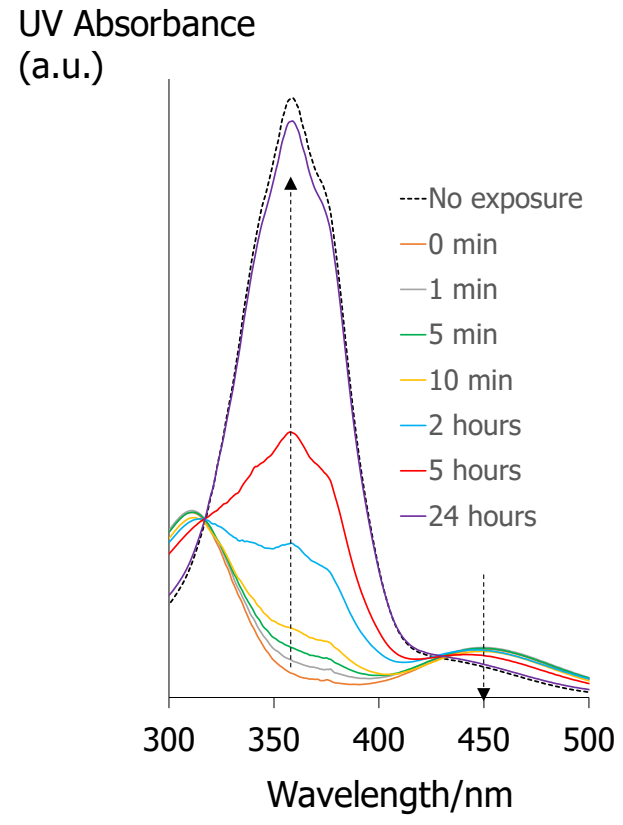

Figure 6. (a) UV-vis spectra of selected terpolymers, including P10-MeOAzB for reference (dotted curve); (b) time-dependent UV-vis spectra of A29/S36/M35, showing its thermal trans-to-cis isomerisation after light exposure at $365 \mathrm{~nm}$. The dotted curve in (b) corresponds to the original spectrum prior to exposure, and arrows indicate the cis-to-trans thermal relaxation with time, $t$.

Upon irradiation at $365 \mathrm{~nm}$, the azobenzene units in all the terpolymers undergo trans-to-cis photoisomerisation. The $\pi-\pi^{*}$ absorbance band in their UV-spectra decreases dramatically in intensity after exposure, whereas a slight increase in the intensity of the $450 \mathrm{~nm}$ region is observed, see Figure 6(b). When the samples are kept in the dark, the intensity of the $\pi-\pi^{*}$ band increases with time, whereas that of the $n-\pi^{*}$ band decreases. After 24 hours, the 
L. Vanti, S. Mohd Alauddin, N. Fadhilah Binti Kamalul Aripin, M. Giacinti-Baschetti, C.T. Imrie, A. Ribes-Greus, A.

Martínez-Felipe. Ionically conducting and photoresponsive liquid crystalline terpolymers: towards multifunctional electrolytes. European Polymer Journal 2018; 109:124-132

original UV absorption spectra for all terpolymers are fully recovered due to the thermally activated cis-to-trans back isomerisation.

\section{Temperature-dependent conductivity.}

We now discuss the temperature dependence of the ionic conductivities for the 10-

MeOAzB/AMPS/MMA terpolymers, measured using electrochemical impedance spectroscopy, EIS, in isothermal steps on cooling the samples from the isotropic melt. The occurrence of $d c$ conductivity, $\sigma_{\mathrm{dc}}$, was detected from the Nyquist plots of the complex impedance, $Z^{*}=Z^{\prime}+i Z^{\prime \prime}$, and more specifically by the appearance of a spike with the real impedance axis, $Z^{\prime}$ (see Figure 7, inset). The $\sigma_{\mathrm{dc}}$ values were obtained from plateaus of the real component of the complex conductivity, calculated as $\sigma^{\prime}=w \cdot \varepsilon "$, when plotted as a function of the frequency, $f$, Figure 7, and the results are shown as Arrhenius plots in

\section{Figure 8.}

Terpolymers with low AMPS contents do not exhibit appreciable direct current conductivity, $d c$, and this suggests that a minimum threshold concentration of ionisable groups is required to achieve net charge transfer across these electrolytes. The presence of higher contents of sulfonic acid groups from AMPS side chains in the terpolymers promotes the appearance of plateaus in the $\log \left(\sigma^{\prime}\right)$ vs $\log (f)$ curves, indicative of long-range conductivity. According to the FT-IR spectra, a number of these sulfonic acid groups may be deprotonated in the 10-MeOAzB/AMPS/MMA terpolymers, suggesting that the conductivity in these samples could be driven by a combination of hydrogen bonding and ionic charges. 
L. Vanti, S. Mohd Alauddin, N. Fadhilah Binti Kamalul Aripin, M. Giacinti-Baschetti, C.T. Imrie, A. Ribes-Greus, A.

Martínez-Felipe. Ionically conducting and photoresponsive liquid crystalline terpolymers: towards multifunctional electrolytes. European Polymer Journal 2018; 109:124-132

In the case of A61/S30/M09, A43/S40/M17 and A70/S15/M15, the plateaus in the conductivity plots are well-defined only above the glass transition, and it was not possible to obtain reliable values for $\sigma_{\mathrm{dc}}$ in the smectic glasses. Conductivities for these samples at high temperatures fall within the range $10^{-8}$ to $10^{-10} \mathrm{~S} \cdot \mathrm{cm}^{-1}$. A09/S85/M06 and A29/S36/M35, on the other hand, exhibit considerably higher conductivity values than the rest of samples, between $10^{-4}$ to $10^{-8} \mathrm{~S} \cdot \mathrm{cm}^{-1}$, and measurable in all the range of temperatures under study. Whereas the high conductivities for A09/S85/M06 could be somehow expected due to the high content of AMPS ionisable groups $(\sim 85 \%, \mathrm{~mol}){ }^{63}$, the $\sigma_{\mathrm{dc}}$ values of A29/S36/M35 are surprisingly high, and we will return to this observation later.

The activation energies, $E_{a}$, for the direct current conductivity, $\sigma_{\mathrm{dc}}$, were obtained from the Arrhenius plots in Figure 8, and the results are depicted in Table 3. Samples show linear trends for $\log \left(\sigma_{\mathrm{dc}}\right)$ in the liquid crystalline phases, giving $E_{a}$ values within the range $60-83 \mathrm{~kJ} \cdot \mathrm{mol}^{-1}$. Above $\mathrm{T}_{\mathrm{LCI}}$, smaller activation energies are obtained, presumably due to a decrease of viscosity of the terpolymers in the isotropic melts. This effect can be considered analogous to the rubbery to liquid transition observed in rubber-like polymers ${ }^{64}$, which is attributed to a decrease in the local viscosity due to removal of certain local-like interactions. In our case, the disappearance of the anisotropic interactions between mesogenic units at the clearing temperature may further enhance the conductivity of the 10MeOAzB/AMPS/MMA terpolymers by an increase in their local mobility. The lowest activation energies were obtained for A09/S85/M06, whose Arrhenius plot displays a combination of two linear ranges, with the intersect coinciding with the glass transition of the terpolymer, $T_{g} \sim 70^{\circ} \mathrm{C}$. For this sample $T_{g}$ seems to be the onset of a melt state where the conductivity is further enhanced, see the activation energies in Table 3. 
L. Vanti, S. Mohd Alauddin, N. Fadhilah Binti Kamalul Aripin, M. Giacinti-Baschetti, C.T. Imrie, A. Ribes-Greus, A.

Martínez-Felipe. Ionically conducting and photoresponsive liquid crystalline terpolymers: towards multifunctional electrolytes. European Polymer Journal 2018; 109:124-132

In general terms, the absence of a fast drop in the $\sigma_{\mathrm{dc}}$ values on cooling towards the $\mathrm{T}_{\mathrm{g}}$ of the terpolymers in Figure 8, precludes a Vogel-Fulcher-Tammann (VFT) behaviour of these samples, and indicates that the conductivity is not strongly coupled to segmental motions. The decoupled character of the conductivity could be explained by the activation of secondary relaxations located in the $10-\mathrm{MeOAzB}$ side chains, which can promote ion hopping $^{17,65}$. In the case of the amorphous A09/S85/M06, the presence of small amounts of mesogens may have a plasticizing effect and reduce the local viscosity expected by the number of polar interactions between AMPS units. For A29/S36/M35, the activation energies are larger, and the conductivity values below $\mathrm{T}_{\mathrm{LCI}}$ are lower than for A09/S85/M06, but this sample presents the advantage to exhibit liquid crystalline phases that can be used to create anisotropic pathways for ion conduction. Thus, the structural features of this particular terpolymer, where mesogenic, sulfonic and methyl methacrylate units are balanced, see Figure 4(b), may result in enhanced ionic conductivities.

Table 3. Activation energies for the conductivity process in the 10MeOAzB/AMPS/MMA terpolymers, $\mathrm{Ea}\left(\sigma_{\mathrm{dc}}\right)$, calculated in the isotropic and smectic ranges.

\begin{tabular}{|c|c|c|c|}
\hline \multirow{2}{*}{ Sample } & \multirow{2}{*}{ AX/SY/MZ } & \multicolumn{2}{|c|}{$\mathbf{E a}_{\mathbf{a}}\left(\sigma_{\mathrm{dc}}\right) / \mathbf{k J}^{*} \mathbf{m o l}^{-1}$} \\
\cline { 3 - 4 } & & Isotropic & Smectic \\
\hline$\# 1$ & A70/S15/M15 & 58.78 & 82.26 \\
\hline$\# 5$ & A61/S30/M09 & 48.50 & - \\
\hline$\# 6$ & A29/S36/M35 & 60.05 & 66.25 \\
\hline$\# 7$ & A43/S40/M17 & - & 64.36 \\
\hline$\# 8$ & A09/S85/M06 & $24.02^{*}$ & \\
\hline & & $51.31^{* *}$ & \\
\hline
\end{tabular}

$* \mathrm{~T}>80^{\circ} \mathrm{C}, * * \mathrm{~T}<80^{\circ} \mathrm{C}$ 
L. Vanti, S. Mohd Alauddin, N. Fadhilah Binti Kamalul Aripin, M. Giacinti-Baschetti, C.T. Imrie, A. Ribes-Greus, A. Martínez-Felipe. Ionically conducting and photoresponsive liquid crystalline terpolymers: towards multifunctional electrolytes. European Polymer Journal 2018; 109:124-132

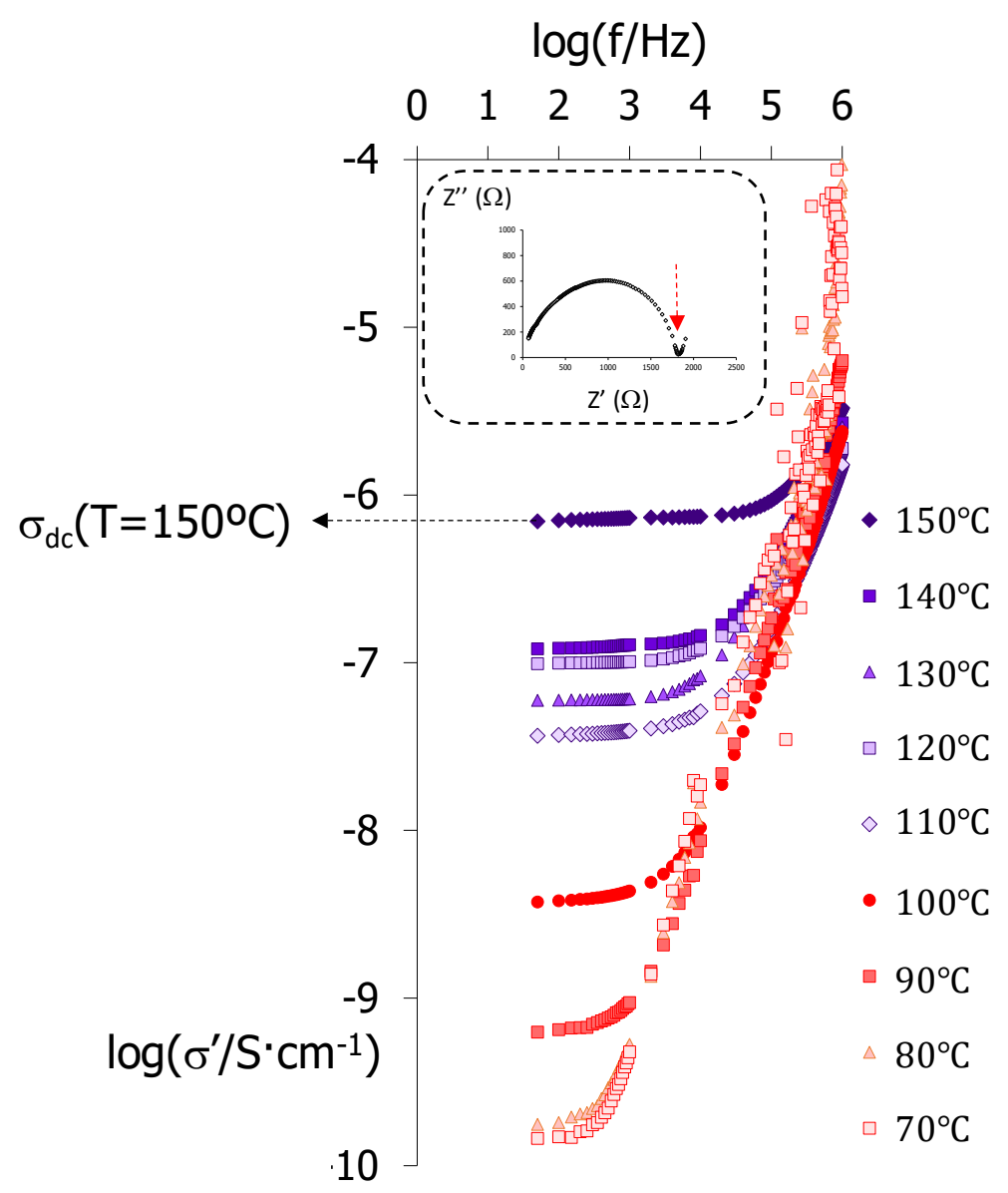

Figure 7. Double logarithmic plots of the real component, $\sigma^{\prime}$, of the complex conductivity of A29/S36/M35, $\sigma^{*}=\sigma^{\prime}+i \sigma^{\prime \prime}$, as a function of the frequency, measured in isothermal steps $\left({ }^{\circ} \mathrm{C}\right)$ on cooling, and estimation of $\sigma_{\mathrm{dc}}$ at $\mathrm{T}=150^{\circ} \mathrm{C}$. Dotted arrow in the inset shows the spike in the impedance Nyquist plot, indicative of $d c$ conductivity. 
L. Vanti, S. Mohd Alauddin, N. Fadhilah Binti Kamalul Aripin, M. Giacinti-Baschetti, C.T. Imrie, A. Ribes-Greus, A. Martínez-Felipe. Ionically conducting and photoresponsive liquid crystalline terpolymers: towards multifunctional electrolytes. European Polymer Journal 2018; 109:124-132

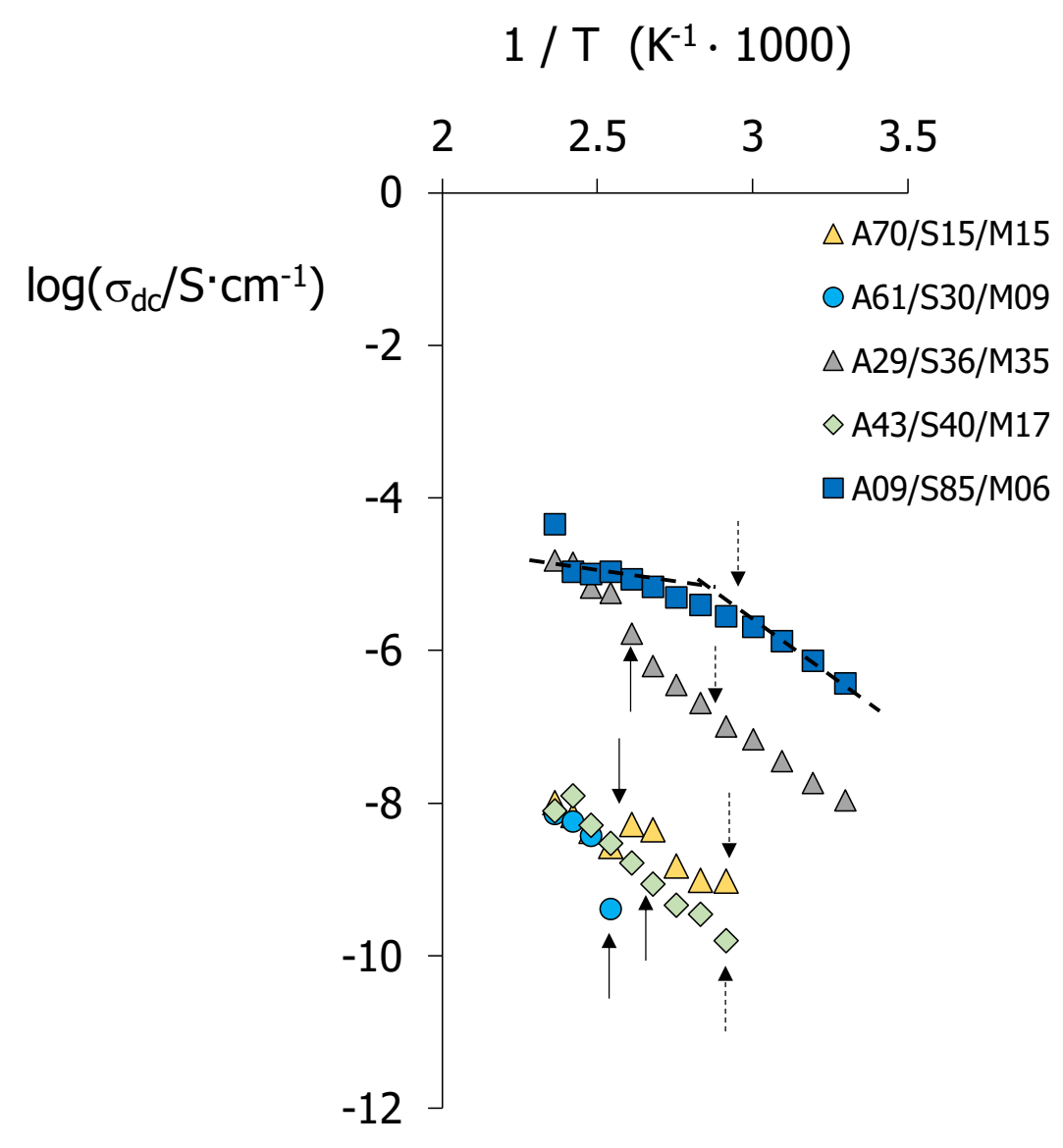

Figure 8. Arrhenius plots of the $d c$ conductivity measured for the 10-

MeOAzB/AMPS/MMA terpolymers. Dotted arrows indicate the glass transition temperatures and solid arrows, clearing temperatures, $\mathrm{T}_{\mathrm{LCI}}$, taken from Table 2.

Dotted lines represent the linear ranges for A09/S85/M06. 
L. Vanti, S. Mohd Alauddin, N. Fadhilah Binti Kamalul Aripin, M. Giacinti-Baschetti, C.T. Imrie, A. Ribes-Greus, A.

Martínez-Felipe. Ionically conducting and photoresponsive liquid crystalline terpolymers: towards multifunctional electrolytes. European Polymer Journal 2018; 109:124-132

\section{CONCLUSIONS}

The 10-MeOAzB/AMPS/MMA terpolymers form smectic phases stabilised by microphase separation between polar and non-polar regions, even at considerably low concentrations of 10-MeOAzB mesogenic units. At sufficiently large contents of AMPS units, the sulfonic acid groups form aggregates constrained between the smectic layers, promoting ionic conductivity in the terpolymers. The presence of MMA groups rapidly reduces the liquid crystal stability and range of the terpolymers by diluting the anisotropic interactions between $10-\mathrm{MeOAzB}$ side-chains, but also reduces hydrogen bonding between AMPS groups near the backbone. This latter effect, together with the formation of liquid crystalline phases, may contribute to increase the local mobility and ultimately promote decoupled ionic conductivity from segmental motions in the terpolymers ${ }^{66}$. The promising conductivity values obtained within the liquid crystal phases and the light responsive character, make the 10MeOAzB/AMPS/MMA terpolymers attractive candidates as electrolytes whose transport properties can be optimised via their changes in their ultrastructure using external stimuli.

ACKNOWLEDGMENTS. The authors thank the financial support of the Generalitat Valenciana, through the Grisolia and Forteza programs, and the Spanish Ministry of Science and Innovation, through the Research Projects ENE2007-67584-C03 and UPOVCE-3E-013 and the awarding of two FPI and FPU pre-doctoral grants. AMF and NFBKA would like to thank the Royal Academy of Engineering for the award of the Newton Research Collaboration Programme grant NRCP1516/4/61. 
L. Vanti, S. Mohd Alauddin, N. Fadhilah Binti Kamalul Aripin, M. Giacinti-Baschetti, C.T. Imrie, A. Ribes-Greus, A. Martínez-Felipe. Ionically conducting and photoresponsive liquid crystalline terpolymers: towards multifunctional electrolytes. European Polymer Journal 2018; 109:124-132

\section{References}

1. Pereira EC, Cuesta A. A personal perspective on the role of electrochemical science and technology in solving the challenges faced by modern societies. J Electroanal Chem 2016 NOV 1;780:355-9.

2. Deluca NW, Elabd YA. Polymer electrolyte membranes for the direct methanol fuel cell: A review. Journal of Polymer Science Part B-Polymer Physics 2006 Aug 15;44(16):2201-25.

3. Schubert US. Polymers for energy storage. Polymer 2015 JUN 26;68:308-9.

4. Young W, Kuan W, Epps,Thomas H.,,III. Block copolymer electrolytes for rechargeable lithium batteries. Journal of Polymer Science Part B-Polymer Physics 2014 JAN 1;52(1):1-16.

5. Hickner M, Ghassemi H, Kim Y, Einsla B, McGrath J. Alternative polymer systems for proton exchange membranes (PEMs). Chem Rev 2004 OCT;104(10):4587-611.

6. Martinez-Felipe A, Imrie CT, Ribes-Greus A. Spectroscopic and thermal characterization of the swelling behavior of nafion membranes in mixtures of water and methanol. $\mathrm{J}$ Appl Polym Sci 2013 JAN 5 2013;127(1):246-56.

7. Mauritz KA, Moore RB. State of understanding of nafion. Chemical Reviews 2004 Oct;104(10):4535-85.

8. Kreuer K, Portale G. A critical revision of the nano-morphology of proton conducting ionomers and polyelectrolytes for fuel cell applications. Advanced Functional Materials 2013 NOV 20;23(43):5390-7.

9. Kreuer K. Aspects of the formation and mobility of protonic charge carriers and the stability of perovskite-type oxides. Solid State Ionics 1999 OCT;125(1-4):285-302.

10. KREUER K, RABENAU A, WEPPNER W. Vehicle mechanism, a new model for the interpretation of the conductivity of fast proton conductors. Angewandte ChemieInternational Edition in English 1982;21(3):208-9.

11. Li X, Faghri A. Review and advances of direct methanol fuel cells (DMFCs) part I: Design, fabrication, and testing with high concentration methanol solutions. Journal of Power Sources 2013 Mar 15;226:223-40.

12. Bahrami H, Faghri A. Review and advances of direct methanol fuel cells: Part II: Modeling and numerical simulation. Journal of Power Sources 2013 May 15;230:30320.

13. Shin DW, Guiver MD, Lee YM. Hydrocarbon-based polymer electrolyte membranes: Importance of morphology on ion transport and membrane stability. Chem Rev 2017 MAR 22;117(6):4759-805. 
L. Vanti, S. Mohd Alauddin, N. Fadhilah Binti Kamalul Aripin, M. Giacinti-Baschetti, C.T. Imrie, A. Ribes-Greus, A. Martínez-Felipe. Ionically conducting and photoresponsive liquid crystalline terpolymers: towards multifunctional electrolytes. European Polymer Journal 2018; 109:124-132

14. Martinez-Felipe A. Liquid crystal polymers and ionomers for membrane applications. Liquid Crystals 2011 2011;38(11-12):1607-26.

15. Cho B. Nanostructured organic electrolytes. Rsc Advances 2014 2014;4(1):395-405.

16. Stoeva Z, Lu Z, Ingram MD, Imrie CT. A new polymer electrolyte based on a discotic liquid crystal triblock copolymer. Electrochim Acta 2013 MAR 30 2013;93:279-86.

17. Imrie CT, Ingram MD, McHattie GS. Ion transport in glassy side-group liquid crystalline polymer electrolytes. Adv Mater 1999 JUL 9 1999;11(10):832.

18. Imrie CT, Ingram MD. Bridging the gap between polymer electrolytes and inorganic glasses: Side group liquid crystal polymer electrolytes. Molecular Crystals and Liquid Crystals 2000 2000;347:443-54.

19. Yamashita A, Yoshio M, Shimizu S, Ichikawa T, Ohno H, Kato T. Columnar nanostructured polymer films containing ionic liquids in supramolecular onedimensional nanochannels. Journal of Polymer Science Part A-Polymer Chemistry 2015 JAN 15 2015;53(2):366-71.

20. Hoarfrost ML, Segalman RA. Conductivity scaling relationships for nanostructured block copolymer/ionic liquid membranes. Acs Macro Letters 2012 AUG;1(8):937-43.

21. Hoarfrost ML, Tyagi MS, Segalman RA, Reimer JA. Effect of confinement on proton transport mechanisms in block copolymer/ionic liquid membranes. Macromolecules 2012 APR 10;45(7):3112-20.

22. Kim SY, Kim S, Park MJ. Enhanced proton transport in nanostructured polymer electrolyte/ionic liquid membranes under water-free conditions. Nature Communications 2010 OCT;1:88.

23. Gao J, Wang Y, Norder B, Garcia SJ, Picken SJ, Madsen LA, Dingemans TJ. Water and sodium transport and liquid crystalline alignment in a sulfonated aramid membrane. $\mathrm{J}$ Membr Sci 2015 SEP 1 2015;489:194-203.

24. Every HA, Mendes E, Picken SJ. Ordered structures in proton conducting membranes from supramolecular liquid crystal polymers. Journal of Physical Chemistry B 2006 Nov 30;110(47):23729-35.

25. Montane X, Vilasrao Bhosale S, Antonio Reina J, Giamberini M. Columnar liquid crystalline polyglycidol derivatives: A novel alternative for proton-conducting membranes. Polymer 2015 JUN 1;66:100-9.

26. Elabd YA, Napadensky E, Sloan JM, Crawford DM, Walker CW. Triblock copolymer ionomer membranes part I. methanol and proton transport. Journal of Membrane Science 2003 Jun 1;217(1-2):227-42.

27. Ye Y, Choi J, Winey KI, Elabd YA. Polymerized ionic liquid block and random copolymers: Effect of weak microphase separation on ion transport. Macromolecules 2012 Sep 11;45(17):7027-35. 
L. Vanti, S. Mohd Alauddin, N. Fadhilah Binti Kamalul Aripin, M. Giacinti-Baschetti, C.T. Imrie, A. Ribes-Greus, A. Martínez-Felipe. Ionically conducting and photoresponsive liquid crystalline terpolymers: towards multifunctional electrolytes. European Polymer Journal 2018; 109:124-132

28. Kuan W, Remy R, Mackay ME, Epps, Thomas H.,,III. Controlled ionic conductivity via tapered block polymer electrolytes. Rsc Advances 2015;5(17):12597-604.

29. Choi UH, Lee M, Wang S, Liu W, Winey KI, Gibson HW, Colby RH. Ionic conduction and dielectric response of poly(imidazolium acrylate) ionomers. Macromolecules 2012 May 8;45(9):3974-85.

30. Martinez-Felipe A, Lu Z, Henderson PA, Picken SJ, Norder B, Imrie CT, Ribes-Greus A. Synthesis and characterisation of side chain liquid crystal copolymers containing sulfonic acid groups. Polymer 2012 Jun 7;53(13):2604-12.

31. Martinez-Felipe A, Imrie CT, Ribes-Greus A. Study of structure formation in side-chain liquid crystal copolymers by variable temperature fourier transform infrared spectroscopy. Industrial \& Engineering Chemistry Research 2013 Jul 3;52(26):8714-21.

32. Martinez-Felipe A, Badia JD, Santonja-Blasco L, Imrie CT, Ribes-Greus A. A kinetic study of the formation of smectic phases in novel liquid crystal ionogens. European Polymer Journal 2013 JUN 2013;49(6):1553-63.

33. Matsui J, Miyata H, Hanaoka Y, Miyashita T. Layered ultrathin proton conductive film based on polymer nanosheet assembly. Acs Applied Materials \& Interfaces 2011 MAY;3(5):1394-7.

34. Sato T, Hayasaka Y, Mitsuishi M, Miyashita T, Nagano S, Matsui J. High proton conductivity in the molecular interlayer of a polymer nanosheet multilayer film. Langmuir 2015 MAY 12;31(18):5174-80.

35. Yabu H, Matsui J, Hara M, Nagano S, Matsuo Y, Nagao Y. Proton conductivities of lamellae-forming bioinspired block copolymer thin films containing silver nanoparticles. Langmuir 2016 SEP 20;32(37):9484-91.

36. Pebalk D, Barmatov E, Shibayev V. Liquid crystalline ionomers as a new class of mesomorphous polymeric systems. Usp Khim 2005;74(6):610-33.

37. Nikonorova NA, Barmatov EB, Barmatova MV, Pebalk DA, Diaz-Calleja R. Local modes of molecular mobility in comb-shaped liquid crystalline ionomers containing alkaline metal ions. European Polymer Journal 2008 Nov;44(11):3806-16.

38. Li W, Kuang T, Jiang X, Yang J, Fan P, Zhao Z, Fei Z, Zhong M, Chang L, Chen F. Photoresponsive polyelectrolyte/mesoporous silica hybrid materials with remotecontrollable ionic transportation. Chem Eng J 2017 AUG 15;322:445-53.

39. Huang Y, Zhu M, Huang Y, Pei Z, Li H, Wang Z, Xue Q, Zhi C. Multifunctional energy storage and conversion devices. Adv Mater 2016 OCT 12;28(38):8344-64.

40. Poutanen M, Ikkala O, Priimagi A. Structurally controlled dynamics in azobenzenebased supramolecular self-assemblies in solid state. Macromolecules 2016 JUN 14;49(11):4095-101. 
L. Vanti, S. Mohd Alauddin, N. Fadhilah Binti Kamalul Aripin, M. Giacinti-Baschetti, C.T. Imrie, A. Ribes-Greus, A. Martínez-Felipe. Ionically conducting and photoresponsive liquid crystalline terpolymers: towards multifunctional electrolytes. European Polymer Journal 2018; 109:124-132

41. Iamsaard S, Asshoff SJ, Matt B, Kudernac T, Cornelissen JJLM, Fletcher SP, Katsonis N. Conversion of light into macroscopic helical motion. Nature Chemistry 2014 MAR;6(3):229-35.

42. Paterson DA, Xiang J, Singh G, Walker R, Agra-Kooijman DM, Martinez-Felipe A, Gan M, Storey JMD, Kumar S, Lavrentovich OD, et al. Reversible isothermal twist-bend nematic-nematic phase transition driven by the photoisomerization of an azobenzenebased nonsymmetric liquid crystal dinner. J Am Chem Soc 2016 APR 27;138(16):52839.

43. Concellon A, Blasco E, Pinol M, Oriol L, Diez I, Berges C, Sanchez-Somolinos C, Alcala R. Photoresponsive polymers and block copolymers by molecular recognition based on multiple hydrogen bonds. Journal of Polymer Science Part A-Polymer Chemistry 2014 NOV 15 2014;52(22):3173-84.

44. Chaganava I, Kilosanidze B, Kakauridze G, Oriol L, Pinol M, Martinez-Felipe A. Induction of the vector polyphotochromism in side-chain azopolymers. Journal of Photochemistry and Photobiology A: Chemistry 2017.

45. Chaganava I, Kilosanidze B, Kakauridze G, Oriol L, Pinol M, Martinez-Felipe A. Photoanisotropy in polarization-sensitive polymer materials based on the media with covalently-bonded components. Organic Photonic Materials and Devices Xix 2017;10101:UNSP 101010T.

46. IMRIE C, KARASZ F, ATTARD G. The effect of molecular-weight on the thermalproperties of polystyrene-based side-chain liquid-crystalline polymers. Journal of Macromolecular Science-Pure and Applied Chemistry 1994;A31(9):1221-32.

47. CRAIG A, IMRIE C. Effect of spacer length on the thermal-properties of side-chain liquid-crystal poly(methacrylate)s. Journal of Materials Chemistry 1994 NOV;4(11):1705-14.

48. SCHLEEH T, IMRIE C, RICE D, KARASZ F, ATTARD G. Ultrastructure studies of polystyrene-based side-chain liquid-crystalline copolymers containing charge-transfer groups. Journal of Polymer Science Part A-Polymer Chemistry 1993 JUN;31(7):185969.

49. Li G, Zhao C, Li X, Qi D, Liu C, Bu F, Na H. Novel side-chain-type sulfonated diphenyl-based poly(arylene ether sulfone)s with a hydrogen-bonded network as proton exchange membranes. Polymer Chemistry 2015;6(32):5911-20.

50. Cook AG, Inkster RT, Martinez-Felipe A, Ribes-Greus A, Hamley IW, Imrie CT. Synthesis and phase behaviour of a homologous series of polymethacrylate-based sidechain liquid crystal polymers. European Polymer Journal 2012 APR 2012;48(4):821-9.

51. Fryer D, Peters R, Kim E, Tomaszewski J, de Pablo J, Nealey P, White C, Wu W. Dependence of the glass transition temperature of polymer films on interfacial energy and thickness. Macromolecules 2001 JUL 31;34(16):5627-34. 
L. Vanti, S. Mohd Alauddin, N. Fadhilah Binti Kamalul Aripin, M. Giacinti-Baschetti, C.T. Imrie, A. Ribes-Greus, A.

Martínez-Felipe. Ionically conducting and photoresponsive liquid crystalline terpolymers: towards multifunctional electrolytes. European Polymer Journal 2018; 109:124-132

52. Martinez-Felipe A, Lu Z, Henderson PA, Picken SJ, Norder B, Imrie CT, Ribes-Greus A. Synthesis and characterisation of side chain liquid crystal copolymers containing sulfonic acid groups. Polymer 2012 JUN 7 2012;53(13):2604-12.

53. IMRIE C, SCHLEEH T, KARASZ F, ATTARD G. Dependence of the transitional properties of polystyrene-based side-chain liquid-crystalline polymers on the chemical nature of the mesogenic group. Macromolecules 1993 FEB 1;26(3):539-44.

54. Martinez-Felipe A, Cook AG, Wallage MJ, Imrie CT. Hydrogen bonding and liquid crystallinity of low molar mass and polymeric mesogens containing benzoic acids: A variable temperature fourier transform infrared spectroscopic study. Phase Transitions 2014 DEC 2 2014;87(12):1191-210.

55. Martinez-Felipe A, Imrie CT. The role of hydrogen bonding in the phase behaviour of supramolecular liquid crystal dimers. J Mol Struct 2015 11/15;1100:429-37.

56. Martinez-Felipe A, Cook AG, Abberley JP, Walker R, Storey JMD, Imrie CT. An FT-IR spectroscopic study of the role of hydrogen bonding in the formation of liquid crystallinity for mixtures containing bipyridines and 4-pentyloxybenzoic acid. Rsc Advances 2016;6:108164-79.

57. Odinokov SE, Iogansen AV. Torsional gamma- $(\mathrm{OH})$ vibrations, fermi resonance 2gamma- $(\mathrm{OH})$-- NU-isotopic effects in IR-spectra of h-complexes of carboxylic-acids with strong bases. Spectrochimica Acta Part a-Molecular Spectroscopy 1972 1972;A 28(12):2343.

58. PERCEC V, HAHN B. Liquid-crystalline polymers containing heterocycloalkanediyl groups as mesogens .7. molecular-weight and composition effects on the phasetransitions of poly(methylsiloxane)s and poly(methylsiloxane-co-dimethylsiloxane)s containing 2-[4-(2(s)-methyl-1-butoxy)phenyl]-5-(11-undecanyl)-1,3,2-dioxaborinane side groups. Macromolecules 1989 APR;22(4):1588-99.

59. PERCEC V, HAHN B, EBERT M, WENDORFF J. Liquid-crystalline polymers containing heterocycloalkanediyl groups as mesogens .8. morphological evidence for microphase separation in poly(methylsiloxane-co-dimethyl-siloxane)s containing 2-[4(2(s)-methyl-1-butoxy)-phenyl]-5-(11-undecanyl)-1,3,2-dioxaborinane side groups. Macromolecules 1990 APR 2;23(7):2092-5.

60. PERCEC V, LEE M. Molecular engineering of liquid-crystalline polymers by living polymerization .20 . synthesis and characterization of binary copolymers of [11-(4'cyanobiphenyl-4-yloxy)undecanyloxy]ethylene with normal-butyl vinyl ether, and of 2[(4'-cyanobiphenyl-4-yl)oxy] ethyl vinyl ether with (normal-butoxy)ethylene. Journal of Materials Chemistry 1992 JUN;2(6):617-23.

61. KUMAR G, NECKERS D. Photochemistry of azobenzene-containing polymers. Chem Rev 1989 DEC;89(8):1915-25.

62. Concellon A, Blasco E, Martinez-Felipe A, Martínez JL, Šics I, Ezquerra TA, Nogales A, Pinol M, Oriol L. Light-responsive self-assembled materials by supramolecular postfunctionalization via hydrogen bonding of amphiphilic block copolymers. 2016. 
L. Vanti, S. Mohd Alauddin, N. Fadhilah Binti Kamalul Aripin, M. Giacinti-Baschetti, C.T. Imrie, A. Ribes-Greus, A.

Martínez-Felipe. Ionically conducting and photoresponsive liquid crystalline terpolymers: towards multifunctional electrolytes. European Polymer Journal 2018; 109:124-132

63. COELHO R. On the static permittivity of dipolar and conductive media - an educationalapproach. J Non Cryst Solids 1991 JUN;131:1136-9.

64. Angell C, Imrie C, Ingram M. From simple electrolyte solutions through polymer electrolytes to superionic rubbers: Some fundamental considerations. Polym Int 1998 SEP;47(1):9-15.

65. McHattie GS, Imrie CT, Ingram MD. Ionically conducting side chain liquid crystal polymer electrolytes. Electrochim Acta 1998 1998;43(10-11):1151-4.

66. Kim O, Jo G, Park YJ, Kim S, Park MJ. Ion transport properties of self-assembled polymer electrolytes: The role of confinement and interface. Journal of Physical Chemistry Letters 2013 JUL 4;4(13):2111-7. 